Wilfrid Laurier University

Scholars Commons @ Laurier

Spring 1995

\title{
Partnerships Between Community Residents and Professionals: Issues of Power and Social Class Across the Lifespan of Neighbourhood Organizations
}

\author{
Barbara Derksen \\ Wilfrid Laurier University \\ Geoffrey Nelson \\ Wilfrid Laurier University, gnelson@wlu.ca
}

Follow this and additional works at: https://scholars.wlu.ca/psyc_faculty

Part of the Psychiatry and Psychology Commons

\section{Recommended Citation}

Derksen, Barbara and Nelson, Geoffrey, "Partnerships Between Community Residents and Professionals: Issues of Power and Social Class Across the Lifespan of Neighbourhood Organizations" (1995). Psychology Faculty Publications. 24.

https://scholars.wlu.ca/psyc_faculty/24

This Article is brought to you for free and open access by the Psychology at Scholars Commons @ Laurier. It has been accepted for inclusion in Psychology Faculty Publications by an authorized administrator of Scholars Commons@ Laurier. For more information, please contact scholarscommons@wlu.ca. 


\title{
PARTNERSHIPS BETWEEN COMMUNITY RESIDENTS AND PROFESSIONALS: ISSUES OF POWER AND SOCIAL CLASS ACROSS THE LIFESPAN OF NEIGHBOURHOOD ORGANIZATIONS
}

\author{
BARBARA DERKSEN and GEOFFREY NELSON \\ Wilfrid Laurier University
}

\begin{abstract}
We describe a qualitative study of four neighbourhood centres jointly created by a sponsoring agency and community members to prevent problems in the lives of children and adults in these neighbourhoods. Individual and focus group interviews with staff, community members, and other agency workers were used to develop an understanding of issues involved at various stages across the lifespan of these settings. Two tensions noted in this process were between community members and professionals from the sponsoring organization and between lower-class and middle-class community members. We discuss the implications of these findings for practice in community development.
\end{abstract}

Recently, there has been a growing interest in neighbourhood organizations as vehicles for community development (CD) (Florin \& Wandersman, 1990). The purpose of this research is to understand the relationships between and among community residents and service providers across the various stages of the lifespan of neighbourhood organizations. More specifically, we focus on how people "work together across differences" of power and social class in the development of neighbourhood organizations (Church, 1994). We begin by providing a brief overview of the principles and processes of $\mathrm{CD}$, as related to neighbourhood organizations. We then indicate what we see as some of the gaps in existing research and describe the goals of this research.

There is a core set of values/principles which underlie CD: (a) the intervention process is directed by community members; (b) the strengths, capacities, and active participation of community members is emphasized; (c) $\mathrm{CD}$ is goal directed and focuses on developing programs to meet the needs identified by the community: and (d) the potential for developing mutual support networks and for effecting community change is enhanced when people come together in a CD process (Cary. 1970; Cawley, 1984; Hair \& Walsh-Bowers, 1992; Rothman \& Tropman, 1987).

This research was partially funded by an Initiatory Research Grant from Wilfrid Laurier University. We thank the members of the advisory committec and the researeh participants for sharing their experiences. We also thank the reviewers and lsaac Prilleltensky for their helpful suggestions, Address correspondence regarding this article to the first author at the Community Health Department, P.O. Box 1633, Waterloo, ON N2J $4 \mathrm{~V} 3$ of to the aceond author at the Department of Psychology, Wilfrid Laurier tiniversity, Waterloo, ON N2L $3 \mathrm{C} 5$. 
Much of the literature focuses on the tasks, processes, and systems interaction aspects of CD (Jones \& Silva, 1991), with much less emphasis on power and relationship issues.

One gap in the $\mathrm{CD}$ literature pertains to the relationships between community members and professional service providers in the context of creating neighbourhood centres. Many writers (e.g., McKnight, 1989; Reiff, 1974) have noted the power imbalance between professionals and citizens and the potential harmful effects when professionals operate from an "expert" approach, which emphasizes people's deficiencies. In a qualitative study of neighbourhood-based prevention programs, Pancer and Cameron (1994) found that trust and positive relationships developed between residents and service providers as time passed. Initially, residents felt intimidated by professional language and practices (e.g. . formal meetings) and were resentful that agencies had "too much say" in decision making. Some of the factors that contributed to the shift toward more positive relationships were: opportunities to get to know one another as individuals and to work together as equals, making meetings more informal and fun, open and direct communication when problems arose, increasing the number of residents involved in committees and working groups, and having residents take an active role in the governance and operation of programs.

In terms of the relationships among community members, there is some evidence that participation in neighbourhood organizations is associated with positive relationships with neighbours and a sense of community (Chavis \& Wandersman, 1990; Unger \& Wandersman, 1983). Thus, neighbourhood organizations can provide a setting for the development of supportive relationships among neighbours. However, there has been little investigation of how social class affects the sense of community and the development of relationships among neighbours. Perkins, Florin, Rich, Wandersman, and Chavis (1990) found that residents' income level was associated with a variety of indicators of the social climate of neighbourhoods. High-income residents tend to perceive the social climate of their neighbourhood more favourably than low-income residents. It is also important to consider the social class mix of a neighbourhood. Unger and Wandersman (1985) argued that homogeneity of neighbourhood residents may positively affect neighbourhood identity. On the other hand, neighbourhoods with a heterogeneous composition in terms of social class may pose challenges for the development of neighbouring relationships and sense of community. Clearly the role of social and economic inequality among neighbourhood residents in the creation of neighbourhood organizations is an important issue that needs further study.

Finally, while it has been emphasized that CD is a process, and guidelines for steps in the intervention process have been outlined (Lackey, Burke. \& Peterson. 1987), there have been very few studies of the stages of community organizations (Bartunek \& Betters-Read, 1987; Sarason, 1972). In fact, we are aware of only one study which has examined the life cycle of neighbourhood organizations (Blum \& Ragab, 1985). Using participant observation and interviews in a six-year study of four activist neighbourhood organizations, Blum and Ragab (1985) reported that the organizations moved through several stages, from developing an ideology and goals to establishing a structure to transitions in leadership, staff, and ideology. 
The purpose of this research is to understand the relationships of people involved in the creation of neighbourhood organizations. More specifically, we aimed to address the gaps in the literature regarding power differences between service providers and community residents and social class differences among community residents. It is our view that inequalities in power and social class are important but overlooked issues in the development of neighbourhood organizations. Moreover, our goal is to study these issues both in depth and over the course of the lifespan of the organizations. Much of the existing literature on neighbourhood organizations has been described in an abstract, theoretical way (e.g., Florin \& Wandersman, 1990). However, these issues become vibrant through the lives of community members, staff, and other service providers. These people experience the ambiguity, emotional intensity, the joys and stresses of the dynamic ebb and flow which characterize neighbourhood organizations. To illuminate these experiences, we decided to use qualitative methods in this investigation. We believe that qualitative methods are best suited to our goals of obtaining the perspectives of community residents, staff, and other service providers in the community on the development of neighbourhood centres over time. Moreover, qualitative methods are valuable in doing research with marginalized people and can draw attention to the important aspects of social context, including power and social class (Kirby \& McKenna, 1989).

\section{METHOD}

\section{Research Context}

The neighbourhood centres that form the basis of this study were initiated by the community services department of a children's mental health centre. This centre has developed a framework for intervention that combines four distinct but interrelated concepts: social competence, social support, adult education, and community development. The vehicle for the realization of this intervention framework is the neighbourhood centre. Currently there are four neighbourhood centres that have been in operation for $16,10,6$, and 4 years, respectively.

These neighbourhood centres are defined by their geographic boundaries. One centre shares space with another neighbourbood organization in a community centre, while the other three centres are located in townhouse units in public housing complexes. All of the neighbourhoods share the characteristics of housing a higher percentage of low-income residents, single-parent families, and residents with lower levels of education than the city or provincial average. All four neighbourhoods are predominantly white.

\section{Advisory Committee}

An advisory committee with membership from each of the neighbourhood organizations was formed to provide input into the conception, design, implementation, and interpretation of this research. The committee was composed of two staff and four community residents, all of whom are women. Members of the committee formed a valuable link between the research project and the various neighbourhood centres, providing information, feedback and sharing the findings of the research. The advisory committee selected potential participants for individ- 
ual or focus group interviews. Selection was based on how long someone had been involved with a neighbourhood centre (so that he/she would be able to provide a perspective that spanned the life cycle of organizations) and whether the person had been involved in more than one centre.

\section{Case Study Methodology}

We used a case study methodology. Yin (1989) defines a case study as "an empirical inquiry that investigates a contemporary phenomenon within its real-life context when the boundaries between the phenomenon and context are not clearly evident and in which multiple sources of evidence are used" (p.23). This approach provided an in-depth description of each of the neighbourhood organizations which in turn helped to elucidate issues of power and social class across the lifespan of neighbourhood organizations. Hence the research is grounded in the experiences of the participants and staff.

\section{Sample and Interviews}

Individual interviews. An interview guide was used for individual interviews. This approach provided a general outline of the issues that were covered with each participant but did not predetermine the specific wording or ordering of questions. The questions in the interview guide were organized chronologically and covered the broad categories: activities, decision making, organizational structure, relationships, personal involvement, and critical issues, All of the interviews were conducted by the first author and tape recorded for later transcription.

\section{TABLE 1}

Methods and Numbers of People Who Provided Information

\begin{tabular}{lcc} 
& Staff & Volunteers \\
\hline Individual Interviews (13) & 9 & 4 \\
Centre Focus Groups (4) & 2 & 13 \\
Service Provider Focus Group (1) & 6 & -
\end{tabular}

Focus group interviews. Focus group interviews were conducted at each of the neighbourhood centres. One additional group was conducted with service providers (school principal, housing authority staff, city staff) who have regular contact with at least one neighbourhood centre. The focus groups ranged in size from two to five members. Participants consented to having the session tape recorded and the responses were also recorded on flip charts.

All participants in either the individual interviews or focus groups were predominantly women between the ages of approximately 25 and 50 years. The one exception was the focus group of service providers in which two men participated. The staff included: past and present directors of the community services department, program managers, and community workers. The four volunteers included three current members and one past member of the boards of each of the respective neighbourhood associations. 


\section{Data Analysis}

The first author reviewed the transcripts of all interviews by listening to the tape and reading the transcript to make corrections to errors made in transcription. Once the interviews were transcribed, they were returned to the people interviewed to make additions, deletions, or corrections. Transcripts were coded using open coding (Strauss \& Corbin, 1990). The first author began by coding a small piece of the data, a sentence or a paragraph, and giving it a descriptive label or name. These codes were then sorted into the corresponding neighbourhood centre and stage of development. Next we focused on one stage and used the interview guide to establish some preliminary categories into which to sort the data (e.g.. staff role, organizational structure). Hence for each stage we developed an overall data chart with the categories, stages and the codes from the transcripts for each centre. The emerging overall organizational framework that helped to frame the data had to do with issues, activities, and roles related to either tasks, processes, or relationships.

The first author combined all of the responses to each of the questions from the focus groups (the neighbourhood groups and service-provider groups) and coded these data. These data were then used to confirm the emerging analysis from the transcripts and also to add more description to the tasks, processes, and relationships described in the interviews.

\section{Caveats}

Although it is helpful to understand developmental progression in stages, it is important to remember that the assignment of stages is artificial; their boundaries are not distinct; and it is often difficult to sharply delineate between stages (Sarason, 1972). Developmental progression is not always linear or straightforward, rather there is an ebb and flow of moving forward and backward. Another issue in doing research that spans 16 years is an awareness and a sensitivity to not imposing a 1994 perspective on events that occurred in 1978. Many respondents noted how much $\mathrm{CD}$ work has changed over this time period and how in retrospect they would have done some things differently.

\section{Feedback}

Individuals who were interviewed were provided a copy of their interview transcripts to review and to make any additions or deletions. Once an initial draft of the report was completed, they reviewed any personal quotations in the context of the document and at the end of the analysis they received a summary of the research. Participants in focus groups received a summary of the focus group discussion and a copy of the research summary. At the conclusion of the research the advisory committee reviewed the research summary and helped to plan a presentation/planning meeting for the neighbourhood associations involved in the research. The presentation/planning day was held with members from each of the neighbourhood associations and some members who participated in the individual interviews. 


\section{RESULTS AND DISCUSSION}

It is acknowledged that the tasks and processes are an essential part of $\mathrm{CD}$ and the life of neighbourhood organizations. In this paper, these tasks and processes are discussed only very briefly to provide a context in which to describe particular relationships that are the focus of the paper: (a) the relationships between service providers from the sponsoring organization and community members, and (b) the relationships among community members in the organization. These relationships are highlighted across the lifespan of these organizations. The stages in the lifespan are: "getting started," "working together," "coming into our own," and "on our own." The stages were originally conceptualized by the sponsoring organization and these categories were developed out of the data collected in this research that focuses on the tasks, processes, and relationships.

\section{Relationships Between Community Members and the Sponsoring Agency Across the Lifespan}

\section{Getting Started}

The tasks during this stage focus on the tools and resources necessary to get the centre started. The tools are the needs assessment techniques and prevention philosophy of the sponsoring agency. The resources are physical structures to house the centre (usually a townhouse in a public housing complex), funding, staff, and volunteers. In the "getting started" stage, the balance between task and process is more heavily weighted toward process. The processes are focused on recruiting volunteers, how they begin to work together, and how volunteers work with staff.

Who's in charge? The category "who's in charge" captures the extent of community input in the selection of the neighbourhood as a site for a new neighbourhood centre and the dimension of power and control in the relationship with the sponsoring agency and its staff.

The kind and type of community input into the selection of a site for a new community centre changed significantly over the years. For instance, the choice of the first centre was essentially made by the staff of the sponsoring agency guided by their assessment techniques. When funding proposals were written for increasing staffing, this too was staff-driven. At the second and subsequent centres, the preliminary selection of the site was made by the sponsoring agency in consultation with other service providers and informal leaders of the neighbourhood were included. In the most recent centre, the sponsoring agency formed an advisory committee that would give direction to and sanction the development of a neighbourhood centre at that site. Both the number of staff and staff behaviour influence the perceptions of who is in control. Two staff seem necessary for providing support to residents, but more than two makes the centre seem too staffcentred or professional. A volunteer noted:

One of their major complaints, ... the professionals told us what we needed, Yes, some parents were lacking in parenting skills and the parenting programs were needed; that $I$ agree with, but some felt that they were not taking our needs, wishes or desires into consideration. I personally did not feel that way. 
In the most recently developed centre, strategies were used to gather the input of community members. A former staff indicated that:

We wouldn't develop a program that they (community members) did not first identify or support, so there would be no imposed programs on residents.

Friend or foe? captures the ambivalence of forging relationships. Wariness and suspicion of the sponsoring agency is strong in the beginning. A volunteer stated:

Nobody would have anything to do with it, they just thought these people were connected with housing, you know, like, you know, they're a bunch of snitches up here. ...

However, as staff develop trust and relationships with community members by listening and validating, they come to be perceived as trustworthy and credible. To the extent that staff provide tangible support, assist in crises, and link residents to resources, they are seen as friends and allies.

\section{Working Together}

In the "working together" stage, the centres move from ideas into the development of viable organizations. Tasks are related to setting up structures (board, committees) and activities (programs) to respond to community needs. Programs that are developed at the four centres vary according to the self-defined needs of the residents. Volunteers are "learning the ropes," They become more involved in the management of the centre, and they learn more about the neighbourhood and how to operate programs and meetings.

Overseer versus partner. This category is an extension of the "friend or foe" category from the previous stage. It captures the centre's relationship with the sponsoring agency and its staff. It encompasses the experience of support, setting limits, and the mixed feelings that volunteers experience in their relationships with the sponsor.

The relationship between the sponsoring agency and each of the centres is often characterized by issues of control. In the "working together" stage, volunteers acquire more skills and savvy in the operations of the organization and at times they see the sponsoring agency as controlling. Some members believe that whatever the organization decides to do is all right as long as the sponsoring agency says it's okay. A volunteer said:

What can we do by ourselves? Who's really in control? ... I guess the one that I really heard from someone who's no longer here, that upset her that much, is "I get the feeling that everything's okay as long as the sponsoring agency thinks it's okay, but if we wanted to do something that they didn't think was okay, then it wouldn't be.

The second area in which the sponsoring agency is perceived to exert control is in the management of the centre. This control is exerted in supervision of staff and managing conflict among volunteers. For example, one centre lobbied the municipal government and secured funding to hire a recreation staff during this stage. Although volunteers had input into the hiring of the staff and determining their tasks, the sponsoring agency took over the supervision role rather than the recreation committee. Another incident involved conflicts among board members about the direction of the organization and the type and cost of programs being of- 
fered. The crux of the conflict was the lack of appreciation on the part of some middle-income members of the barriers to involvement faced by lower-income women. The sponsoring agency's involvement in the issue was perceived as the "heavy hand of the sponsoring agency coming down." Hence, volunteers often express confusion over what tasks they can take responsibility for and to what degree they need to consult staff. A volunteer remembered: "I wasn't always sure of what I should involve staff with, .... or what decisions I could make on my own."

Although the category is entilled "overseer vs. partner," the relationship between the volunteers and staff perhaps could be better captured by supervisor (rather than overseer) versus partner. During the "working together stage," there is a more distinct shift in balancing the power and influence between staff and volunteers. As volunteers take on more tasks and increased responsibility, there is a tension between seeing staff as helpers versus doers. Concurrently staff reported that they had to stifle the inclination to do particular things that they can do more quickly on their own because it is important for volunteers to do tasks, even if there is a risk of failure. A volunteer commented:

Some volunteers tend to say "well the staff can do it." So we had to constantly remind them "no, that's not the type of centre we are, . . . we're volunteer driven, and we have to do it. They can help us, but we have to do it."

Another tension in the relationship is volunteers wanting to do more and staff setting limits on the scope and pace of volunteer activities which leads volunteers to feel stymied. A volunteer said:

There would probably have been power struggles. Again the board would want to go ahead,.... They wanted to run a pre-school for 50 children, and staff would have felt more comfortable with them running a pre-school for 25 children. Just things like that, and that also brought out some of the questions, okay, what sort of decisions can we make as a group and what can't we. Sometimes we felt we were being sat on and-we thought we can do this, you know, we can go ahead and do this. So 1 think they were a little nervous that things might get out of control, that we might get too many things on the go, and then volunteers would drop back, and then it would be left to staff support.

Members across the various settings express ambivalent feelings about the relationship between the sponsoring agency and the centres. Although they experience the instances of the sponsoring agency exerting control over the centres, they also reported feeling safe and reassured that the sponsoring agency, a big organization, is behind them. A staff commented: "So again there was some relief that the safety net was there." They also recognize that the sponsoring agency provides support and expertise that they would not have without that relationship. Hence, in the "working together" stage, the sponsoring agency is seen as a safety net as volunteers take increasing responsibility for the centres.

\section{Coming Into Our Own}

The tasks and processes are strongly interrelated at this point. There is an increasing program base and more formalized operations: volunteers become managers and employers: and staff shift even more to a non-directive, support role. In this stage, the centres move toward independence, work to secure funding and to become incorporated. 
Getting ready to incorporate (taking flight without crashing). The category "getting ready to incorporate" encompasses the readiness of centres to become incorporated and the feelings and tensions experienced with the sponsoring agency in negotiating this passage. Despite the presence of readiness indicators (ability to manage the centre and a sense of ownership), the transition between "coming into our own" and "on our own" is rife with tension and ambivalent feelings. A former staff commented:

I think people on one hand felt reassured, because there was a certain safety that big brother was watching, taking care of, no matter what happened the sponsoring agency would be there. When we started talking about separation, and moving away from, there was a panic. And while the (neighbourhood centre) really wanted its independence, at the same time they were terrified of it, and they kept saying well, what if this happens, what if that happens.

While there is excitement and anticipation with the prospect of becoming independent, there is also anxiety. There is concern about the logistics of operating independently, specifically concerns with liability, funding, employment management, and legal responsibilities. There was a constant tension between secking independence and seeking reassurance. A staff said:

I think they're forging their own destiny, but once in a while they still have to look to the sponsoring agency for advice.

Despite these mixed emotions members reported feeling generally supported by the sponsoring agency during this time of transition. However, it is no less anxietyprovoking for the sponsoring agency. A staff commented:

The model, as you know, doesn't give a lot of direction, in terms of how the transitions happen, ... in terms of "what do I let them do?, what do I not let them do?, how involved do we let them get?" ... And so that probably created areas of vagueness and uncertainty, and insecurity for everyone. . . . You had an organization that was looking to the sponsoring agency for leadership, and you had the sponsoring agency sort of saying, . . . "there weren't any ground rules here."

In the "coming into our own" stage, the sponsoring agency is seen as more of an equal partner. This is facilitated by the centre's pursuing independent funding and hiring its own co-ordinator. From the struggling and testing of boundaries of the earlier stages, a more equitable partnership has emerged. For centres, the relationship is more comfortable; they can look to the sponsoring agency for guidance, weigh their advice, but feel free to make their own decisions. A volunteer commented:

The sponsoring agency was not really in favour of us getting into the bingos, because that was again a gambling type situation, but that was a board decision that we made, and they left it with us as our thing. And just little things like that, that really didn't fit into their mandate, but they allowed us to put it in ours. ... They wouldn't say we couldn't do it, but they would suggest maybe we shouldn't do it. ... It was good, because it made us stop and think that maybe we should be thinking more this way. Some things we did agree with them, and other things we said "no, that we really wanted to try it this way," and so we went ahead and they were very receptive to that, it's not a matter of slapping us on the hand or anything like that. 


\section{On Our Own}

At this point, the centres are well known and established in their neighbourhoods. Although maturity is not a steady state, a sense of history and the existence of an infrastructure supports the centre in times of transition.

Balance of power. One of the tensions for organizations in the final stage is maintaining the delicate balancing power between members and the consultant from the sponsoring agency. In the final stage, the relationship between the sponsoring agency and the neighbourhood organization becomes more formalized in a memorandum of agreement which outlines the responsibilities of each party. This memorandum includes a sum of money that comes directly to the sponsoring agency from the funders but is earmarked for the respective autonomous organization. This funding provides a strategic link and supports the sponsoring agency's continued involvement with independent neighbourhood centres, given the vulnerability of some neighbourhood centres and the multiple problems that can arise. The consultant is viewed as a support and advisor to the staff and a mentor and advisor to the board. Nevertheless, the consultant can be caught in an awkward position of being constrained to giving advice rather than direction. A staff said:

But it's a difficult role, particulariy when the staff are new. They don't have a
real sense of what their roles are, and... I'm not an authority for them, in
terms of telling them what do to, and it's frustrating sometimes, because
they're not doing what, perhaps, I think ideally they should be doing as staff at
a neighbourhood association.

The organization's relationship with the sponsoring agency shifts in the final stage and the sponsoring agency is seen as a supportive partner who is able to help put things into perspective for the centre. A volunteer commented:

The sponsoring agency has always been a moral supporter and our pat on the back, our encouraging word. When you're the most frustrated, they say the right things. They put things into perspective.

\section{Discussion}

A tension in the process of community empowerment is the balance of power between the sponsoring agency and the community. The sponsoring agency acts as a catalyst in the community, bringing people together who share a common interest, and contributes resources and support to the process. Since there is a power imbalance between the professional agency and the "at-risk" community, there is a danger of over-valuing the knowledge and skills of paid professionals to the detriment of the knowledge and skills of community members (McKnight, 1989). The first neighbourhood was selected solely by professionals, who defined the neighbourhood as "at risk," a term that is resented by neighbourhood members. Thus, professional labeling and language can have negative effects on the community (McKnight, 1989). With the development of subsequent centres, there bas been an increasing input from a broader range of the community in the selection of neighbourhoods to counteract this problem.

Another barrier to the development of service provider and community resident relationships is the number of staff members. In the first centre that was initiated, there was a preponderance of staff such that residents saw the organization as the staffs rather than theirs. This perception was reinforced by the pro- 
vision of programs that staff thought the residents could benefit from or by staff shaping programs a particular way based on residents' ideas. Hence the very definition of resident involvement was different in the initial centre. In the subsequent centres, there has been a greater sensitivity to the issues of staff control and a trend toward hiring community members. Barker and Gump's (1964) theory of understaffing may be relevant to this issue. When there are not enough staff to do all the work in a setting and when there is a strong ethos of resident participation (Pancer \& Cameron, 1994), pressure is exerted to involve residents more in the operation of the centre. Using community members as paid staff or as volunteers is one way of increasing community participation and power.

Over time, as the centres become more firmly established, a genuine partnership between the community and the sponsoring agency became apparent (Labonté, 1993). Like Pancer and Cameron (1994), we found that positive relationships between service providers and community members developed over time. What community members valued in the service providers were their interpersonal and human qualities, such as listening, moral and tangible support, and respect. These findings are congruent with those of Lord and Hutchison (1993),

Across the development of each of the neighbourhood centres, there has been an increasing appreciation and anticipation of the barriers that professionals must address in fostering authentic community participation. There is an acknowledgment by professionals that the process is not always neat and straightforward. Furthermore, there are deliberate efforts to tackle barriers related to professional language, jargon, and dress (Church, 1992). Concurrently efforts are made by professionals to create informal spaces, to address barriers related to cost and childcare (see Pancer \& Cameron, 1994), and to replace the language of professionals, which encourages control, with dialogue that supports mutuality and reciprocity (Lord \& Hutchison, 1993). Similarly, Pancer and Cameron (1994) found that a deemphasis on professional language, informality and opportunities for people to get to know one another were important in developing positive relationships.

\section{Relationships Among Community Members}

\section{Getting Started}

Us and them=we (Integration). A number of factors that occur at the beginning of a neighbourhood centre set the stage for challenging the integration of various income groups in the work of the centre. These factors include the philosophy of the initiating organization, the provision of space for some neighbourhood centres in public housing complexes, the process of identifying neighbourhood sites for centres, and the existing relationships between the two income groups. The sponsoring agency's philosophy is specifically geared to establishing neighbourhood centres that are not solely focused on low-income areas of the neighbourhood but invite participation from the whole community. One of the reasons for this stance is to draw on a large base of existing community strengths and skills.

Three of the neighbourhood centres are located in public housing complexes and to varying degrees are set off from the surrounding neighbourhood. Often 
people living within the public housing complex would talk about this being only a short-term arrangement, one they hoped to escape. A staff member noted:

It seems as if they can't ever feel proud of living in housing, because the whole society holds public housing-as a bad thing .... that you should be able to do better. And so the people living there internalize that. And it's really sad, because then they tell you bad things about their neighbourhood, because they don't dare tell you something good.

In the beginning stage these neighbourhoods had a reputation of being "bad places to live," places with high rates of crime, vandalism, and drug use. Both people living in the complexes and the surrounding neighbourhood reported that they were afraid of what was happening in the complexes. Those living in the complex reported fear, isolation, and frustration at being "painted with the same brush" as the drug dealers and users. A volunteer recalled; "I remember when I first started I was so desolate. I was shut in, like I never had friends here,"

The experiences of one centre serve to illustrate the integration tension in the "getting started" stage. The first phase of membership included solely residents from within the housing complex. For this particular group of residents there was high enthusiasm, but there were also limited organizational skills and a high degree of mistrust and dissension within the group. A staff member remembered:

The distrust they had for each other was so high that they couldn't work together at the table..... You couldn't get three people in the same room and have a meeting. You could have two in the room, and have a meeting, but not three. The dissent was that great.

In an effort to broaden representation from the neighbourhood and to provide members with an opportunity to learn new skills, members from the surrounding community were recruited. This particular group of residents from the surrounding community were highly skilled and generally well educated. They were accustomed to working independently in church or non-profit groups. A staff member commented:

When we got involved with more economically secure, middle-class families, they had no experience with housing residents, so it was culture shock. Traditionally these families don't come into public housing, and they don't understand the process, so there was distrust now between the two groups that we were trying to make one group of:

A volunteer from outside the neighbourhood noted:

To tell the truth, it was frustrating. The group from outside seemed to be the ones who were used to setting a date for a meeting, setting the time, and showing up. .... And the people from inside the village, always didn't seem to run on the same schedule that we did, like something would come up that they wouldn't be able to attend the meeting, or they didn't get up in time, or their kids were sick, and that was frustrating because we weren't used to having that happen.

The two groups were very different. Each group had a different perception of what had to be done, how to work together in terms of setting meetings, the degree of formality, and how to reach consensus. A staff member noted:

And as we got more people involved in the building process, it went to the other extreme, where people who were educated became quite formal, they wanted to print agendas and write minutes, and the other people weren't ready 
for that; we had people who couldn't read. . . Pieces of paper with agendas threaten people who couldn't read.

The final phase of the volunteer membership in the getting started stage occurred with the arrival of some volunteers from outside of the neighbourhood who could serve as a bridge between the two more diverse groups. These members, both from middle and lower income backgrounds, were able to acknowledge the stresses of the lower-income group and be accepting and non-judgemental. A staff member recalled:

Leadership was a challenge. In the beginning you either had very economically secure, well-educated people, and very very poor people. And very few people bridging that. Gosh, it was hard, so you had a person with post-graduate education trying to work with a lady with grade 5 education, as co-leaders of programs. When the new person joined, she bridged that huge difference. That was very very healthy, in that she brought a perspective which understood both of these extremes.

\section{Working Together}

Integration: We versus me. The issue of integration in the "working together" stage takes place in the ways that volunteers work together, especially at the board level. For all centres, members struggle with how to work together, and deciding who's in charge. While in the "getting started" stage, this tension existed between the members of the housing complex and members from the surrounding neighbourhood, in the "working together" stage this tension is more evident within the core working group. It is more personalized as individual members struggle between directions and decisions that meet their own personal interests but perhaps not the interests of the integrated group. The issue becomes more complex as the group continues to struggle with the integration of members from within the public housing complexes (lover-income members) and members from the surrounding neighbourhood (middle-income members). In some centres there was a tendency for the more middle-income members to want to push ahead, often leaving less skilled members in the background. Hence lower-income members felt intimidated and needed more support in building their confidence to take a more vocal role. A staff observed:

I think maybe some of the lower-income group felt that they had no power against them, that they were very skilled, articulate women, and in fact they were, and that they were just galloping ahead of them.

One example of an issue that was divisive for the groups was subsidized spaces in pre-schools. A staff commented:

You have to have $\mathrm{x}$ number of spaces for those kids whose parents just simply cannot afford to put any money into a program, or maybe chose not to put any money into paying for their child to go to pre-school. . . . That really divided the group up, it was the "haves" and "have nots" almost, and there was a certain group that was saying, .... look at all the people that want to come into this program, and bring children from .... all these really nice neighbourhoods, and you're leaving spaces for kids that may or may not come? Because they're free," And so there was a real issue around the subsidized programming. .... And there was a lot of infighting about it. 


\section{Coming Into Our Own and On Our Own}

Integration: Us and them revisited. While the integration issues discussed in the earlier stages have focused on centres located in public housing complexes, one centre, not located in public housing, also experienced integration tensions. This centre was offered shared space with a group sponsored by the city. Members of the centre perceived members of the other organization as judgemental and prejudiced against lower-income families, One volunteer stated:

The make-up of their board as individuals was different than the make-up of our board as individuals. They thought themselves to be very open, warm, friendly, but they were very prejudiced about people .... that were of lower class than they were. They were extremely offended by other people whose children had behavioural problems.

Clearly the integration issue runs deep and creates challenges for the neighbourhood organization. However, one volunteer remembered these challenges as not completely negative.

Even the tension I didn't see as a real negative thing even at the time, or obviously I wouldn't have continued, you know, it was just something that you had to work with, and keep going.

\section{Discussion}

We found that stresses related to the integration between lower- and middleincome groups were a barrier to a sense of community, as Unger and Wandersman (1985) suggested. While there was a focus on integrating these two groups, the reality was that the lower-income groups were generally segregated in public housing complexes which were set apart from and stigmatized by the surrounding community. It is surprising that issues of poverty and social class have received so little attention in the literature on neighbourhood organizations, since they were clearly identified issues in this study. While structural problems of social and economic inequality are deeply rooted and difficult to change, we found that some centres managed this tension better than others.

Two factors that seem to influence the extent to which neighbourhood groups experience significant tensions between the two income groups are the homogeneity of income distribution and the role of indigenous leaders. Centres where tensions were less problematic were located in neighbourhoods which were much more homogeneous in income levels which is consistent with the observations of Unger and Wandersman (1985). In homogeneous communities, there were people receiving social welfare, but there were also lower-income working families. Without the great variance of income groups, there tended to be a greater sense of shared experiences, stresses, and a common reality which was absent in neighbourhoods which had the richest and poorest living in the same geographic area. Secondly, the leadership in the organization also played a critical role in mediating the tensions. The emergence of strong leaders from the low-income group and/or middle-income women who were sensitive to the experiences of low-income women helped these two groups to work across their differences (Church, 1994). 


\section{IMPLICATIONS FOR PRACTICE}

The findings of the research suggest three broad themes which have implications for practice: (a) consciousness-raising for professionals and community members, (b) reallocation of material and human resources, and (c) the role of conflict in the empowerment process.

\section{Consciousness-raising for Professionals and Community Members}

A myth that pervades the early relationships among members of different social classes is that low-income people are to blame for their lot in life. This myth is internalized by low-income people who blame themselves, as well as by middleand high-income people. One important role then for professional CD workers is to recognize manifestations of this myth and name them as "victim-blaming." As Lord and Hutchison (1993) have argued, "citizens who are devalued must be seen as oppressed and marginalized by society, not simply as clients to be served" (p. 19) by professionals who espouse an empowerment approach to community practice. Professionals can encourage a critical dialogue about the myth of meritocracy (that people get what they deserve) and the inequities in power and social class that exist between people (Prilleltensky, 1994).

This consciousness-raising is necessary to move community members from a motivation based on charity or benevolence to one based on social justice (Rappaport, 1981). Thus, CD practice cannot solely be a set of techniques, rather CD needs to be grounded in an ethic of social justice. Working from an ethic of social justice calls for a radical re-definition of professionals roles and identity (Church, 1992, 1994). In practice, this means that professionals must focus on strengths, encourage listening and dialogue, enter into collaborative partnerships with community members, work with people to reduce systemic barriers, share resources, and support citizen control (Lord \& Hutchison, 1993). Professional training programs and community agencies need to be revamped to provide support for these innovative roles and activities.

\section{Reallocation of Material and Human Resources}

Service agencies and CD workers must allocate funds directly to citizens to make their participation meaningful (Lord \& Hutchison, 1993). Material resources. such as transportation, compensation for mileage and childcare, and honoraria for volunteers, are tangible ways of supporting citizen participation. Hiring people from the neighbourhood to work in CD projects is another promising practice (Pancer \& Cameron, 1994).

The balance of volunteers and paid staff is a critical part of promoting citizen involvement in neighbourhood-based organizations. A small number of staff and a critical mass of volunteers are essential to participation (Barker \& Gump, 1964). Having more volunteers than staff helps to reduce the power imbalance between professionals and citizens. In addition to the critical mass of volunteers is the necessity of low-income indigenous leaders and bridging leaders (i.e., people who live outside public housing but who can work with the diverse membership of the community). We need to learn more about people who are able to build bridges between people from diverse socioeconomic and cultural backgrounds in the 
community. In summary, community agencies need to reallocate tangible resources to directly support low-income community members.

\section{The Role of Conflict in the Empowerment Process}

Our data show that service providers and community members struggle to develop positive working relationships. Since there are inequities in power and social class among community stakeholders, some degree of conflict between these stakeholders is normal and necessary (Labonté, 1993). Conflict presents an opportunity for growth and change. As Church (1992) has noted, conflict is important for uncovering deeply ingrained assumptions and personal investments in the status quo, of which professionnls may be unaware. Thus, conflict can enable professionals and community members to change both their assumptions about themselves and others, and correspondingly, their practices in relationship with others, such as shared decision making and resources.

While there was a shift in power over time from professionals to community members, this process was lengthy and difficult (Lord \& Hutchison, 1993). There were setbacks and tensions at various points throughout the lifespan of the four centres. One implication of this is that professional CD workers must recognize there is no simple recipe for empowerment; rather, empowerment involves a continuous process of learning and development. Thus, there needs to be an emphasis on process and conflict, as well as problem solving and task accomplishment in CD work with neighbourhood centres.

\section{RÉSUMÉ}

Nous présentons les résultats d'une recherche qualitative portant sur quatre organismes de quartier créés par une agence agissant comme ressource et par les membres de la communauté pour prévenir les problèmes pouvant affecter la vie des enfants et des adultes de ces quartiers. Des entrevues individuelles et des focus groups ont été réalisés auprès du personnel intervenant, les membres de la communauté, et d'autres travailleurs de l'agence pour comprendre les problèmes rencontrés aux diverses étapes de vie de ces projets. Deux points de tension apparus dans le processus touchent les relations entre les membres de la communauté et les professionnels de l'agence commanditaire et entre les membres de classe inférieure et ceux de classe moyenne. Ces résultats sont examinés quant à leurs implications pour la pratique du développement communautaire.

\section{REFERENCES}

Barker, R.G., \& Gump, P.V. (1964). Big school, small school. Stanford: Stanford University Press.

Bartunek, J.M., \& Betters-Reed, B.L. (1987). The stages of organizational creation. American Joumal of Community Psychology, 15, 287-303.

Blum, A., \& Ragab, I. (1985). Developmental stages of neighborhood organizations. Social Policy, 15, 21-28.

Cary, L.J. (1970). Community development as a process. Columbia: University of Missouri Press.

Cawley, R. (1984). Exploring the dimensions of democracy in community development. Joumal of Community Development Society, 15, 15-25. 
Chavis, D., \& Wandersman, A. (1990). Sense of community in the urban environment: A catalyst for participation and community development. American Joumal of Community Psychology, 18, 55-82.

Church, K. (1992). Moving over (A commentary on power-sharing). Toronto: Psychiatric Leadership Facilitation Program and Ontario Ministry of Health, Community Mental Health Branch.

Church, K. (1994). Working together across differences. Toronto: Psychiatric Leadership Facilitation Program and Community Resources Consultants of Toronto.

Florin, P., \& Wandersman, A. (1990). An introduction to citizen participation, voluntary organizations, and community development: Insights for empowerment through research. American Joumal of Community Psychology, 18, 41-54.

Hair, H., \& Walsh-Bowers, R. (1992). Promoting the development of a religious congregation through a needs and resource assessment. Joumal of Communiry Psychology, 20, 289-303.

Jones, B., \& Silva, J. (1991). Problem solving, community building, and systems interaction: An integrated practice model for community development. Joumal of Community Development Society, 22, 1-21.

Kirby, S., \& McKenna, K. (1989). Experience, research, social change: Methods from the margins. Toronto: Garamond Press.

Labonté, R. (1993). Community development and partnerships. Canadian Joumal of Public Health, 84, 237-240.

Lackey, A.S., Burke, R., \& Peterson, M. (1987). Healthy communities: The goal of community development. Joumal of Communiry Development Sociery, 18, 1-17.

Lord, J., \& Hutchison, P. (1993). The process of empowerment: Implications for theory and practice, Canadian Joumal of Community Mental Health, $12(1), 5-22$.

McKnight, J.L. (1989). Do no harm: Policy options that meet human needs. Social Policy, 19, 5-15.

Pancer, S.M., \& Cameron, G. (1994). Resident participation in the Better Beginnings, Better Futures Prevention Project: Part I-The impacts of involvement. Canadian Joumal of Community Mental Health, 13(2), 197-211.

Perkins, D.D., Florin, P., Rich, R.C., Wandersman, A., \& Chavis, D.M. (1990). Participation and social and physical environment of residential blocks: Crime and community context. American Joumal of Community Psychology, 18, 83-116.

Prilleltensky, I. (1994). Empowerment in mainstream psychology: Legitimacy, obstacles, and possibilities. Canadian Psychology, 35, 358-374.

Rappaport, J. (1981), In praise of paradox: A social policy of empowerment over prevention. American Joumal of Community Psychology, 9, 1-25.

Reiff, R. (1974). The control of knowledge: The power of the helping professions. Journal of Applied Behavioural Science, 10, 451-461.

Rothman, J., \& Tropman, J.E. (1987). Models of community organization and macto practice perspectives: Their mixing and phasing, In F, Cox, R. Erlich, J. Rothman, \& J. Tropman (Eds.), Strategies of community organization (4th ed., pp. 3-26). Itasca, IL: Peacock.

Sarason, S.B. (1972). The creation of settings and the future societies. San Francisco: Jossey-Bass.

Strauss, A., \& Corbin, J. (1990). Basics of qualitative research: Grounded theory procedures and techniques. Newbury Park, CA: Sage.

Unger, D.G., \& Wandersman, A. (1983). Neighboring and its role in block organizations: An exploratory report. American Joumal of Community Psychology, 13, 139-169.

Unger, D.G., \& Wandersman. A. (1985). The importance of neighbours: The social, cognitive, and affective components of neighbouring. American Joumal of Community Psychology, 13, 139-165.

Yin, R. (1989), Case study research: Design and methods. Newbury Park, CA: Sage. 